\title{
Metabolic abnormality of calf skeletal muscle is improved by localised muscle training without changes in blood flow in chronic heart failure
}

Mitsunori Ohtsubo, Kazuya Yonezawa, Hirotaka Nishijima, Koichi Okita, Akiko Hanada, Tetsuro Kohya, Takeshi Murakami, Akira Kitabatake

\begin{abstract}
Objective-To investigate whether localised skeletal muscle training, which does not have a great influence on the heart, improves abnormalities of calf muscle metabolism in patients with chronic heart failure.

Methods-Seven cardiac patients in New York Heart Association class II and III undertook a random order crossover trial. Training consisted of unilateral calf plantar flexion exercise. Before and after training, the patients' metabolic responses were examined during the calf exercise test with phosphorus-31 nuclear magnetic resonance spectroscopy $\left({ }^{31} \mathbf{P}-\right.$ MRS) and calf blood flow with plethysmography. The new Borg scale was employed as a subjective fatigue scale.

Results-In a constant load exercise test (70\% of maximum load achieved during the incremental exercise), standardised phosphocreatine and intracellular pH decreased less after training $(p<0.05$, repeated measures analysis of variance). The new Borg scale improved significantly after training $(p<0.05)$. Blood flow did not change significantly in either test. Conclusions-In patients with chronic heart failure, localised calf skeletal muscle training improved oxidative capacity without changes in calf blood flow. This training also improved the subjective fatigue scale. This training method may therefore alleviate leg fatigue experienced in daily activities.

(Heart 1997;78:437-443)
\end{abstract}

Keywords: heart failure; magnetic resonance spectroscopy; skeletal muscle; localised training

In patients with chronic heart failure, central haemodynamics improve with vasodilator treatment within the short term, but increases in exercise capacity are delayed for weeks or months. ${ }^{1}$ This suggests that cardiac function is not the sole factor determining exercise capacity. Using phosphorus-31 nuclear magnetic resonance spectroscopy ( $\left.{ }^{31} \mathrm{P}-\mathrm{MRS}\right)$, many investigators have reported that patients with chronic heart failure have abnormal forearm skeletal muscle metabolism, ${ }^{23}$ and Mancini et $a l^{4}$ reported abnormal metabolism in the calf muscle. Sullivan et $a l^{5}$ speculated that periph- eral factors play an important role in exercise capacity in chronic heart failure.

In recent years, investigations into cardiac rehabilitation have suggested that exercise training increases peak oxygen uptake $\left(\dot{\mathrm{V}}_{2}\right)$ of patients with chronic heart failure. ${ }^{6-8}$ Most previous training studies employed large muscle group training such as bicycle exercise. However, some patients may not be able to perform such exercise because of poor cardiac function. Therefore, if patients were able to achieve metabolic improvement in their muscles by localised small muscle group training, which does not have a large influence on haemodynamics, this would be advantageous for them. Though few investigations on localised training have been reported, Minotti $e t a l^{9}$ and Stratton et $a l,{ }^{10}$ using ${ }^{31} \mathrm{P}-\mathrm{MRS}$, conducted controlled trials of single forearm training and found that the abnormal forearm muscle metabolism could be improved by localised training without affecting cardiac function.

In daily life, the activity of cardiac patients is frequently limited because of leg fatigue. Lower extremities are closely related to fundamental daily actions such as walking, sustaining posture, and so on. It is reported that muscle composition $^{11-13}$ and metabolism during exercise ${ }^{14-16}$ are different in the upper and lower extremities. However, in spite of these differences, there have been few training studies focused on the lower extremities. Magnusson et $a l^{17}$ studied localised training in the quadriceps femoris muscle in patients with chronic heart failure and reported that the work capacity of trained muscles increased. Employing a muscle biopsy technique, they also found histochemical changes. This training resulted in some systemic effect, probably because the quadriceps femoris is a relatively large muscle group. Using ${ }^{31} \mathrm{P}$-MRS, Adamopoulos et al ${ }^{18}$ suggested that exercise training with a bicycle ergometer improved calf muscle metabolism during plantar flexion exercise, but this result was derived from large muscle group training. It remain unclear whether localised calf muscle training, as a model for small muscle training, can improve abnormal muscle metabolism in patients with chronic heart failure. Also, there has been no localised training study of leg muscles using ${ }^{31} \mathrm{P}-\mathrm{MRS}$. In the present crossover study, we designed a localised training method in which the ankle joint motion was similar to that in walking, because walking is the most basic action in daily life. 
Using ${ }^{31} \mathrm{P}-\mathrm{MRS}$, we examined the hypothesis that isotonic localised training of the calf muscles improves their metabolism, and whether this training decreased the patients' fatigue scores. If our hypothesis proved correct, then localised calf muscle training may be safely used for cardiac rehabilitation to improve patients' quality of life.

\section{Methods}

STUDY POPULATION

We studied seven stable patients with chronic heart failure caused by idiopathic dilated cardiomyopathy (six men and one woman). The mean (SD) age of patients was 56.9 (5.6) years (range 52 to 66 years), height 166.6 (3.3) $\mathrm{cm}$, and weight $69.4(8.0) \mathrm{kg}$. Six were in New York Heart Association functional class II and the other was in class III. We explained the details of this study to the patients and informed consent was obtained. The institutional committee on human research approved the study protocol.

All patients were taking diuretics, four were on digitalis, five were on angiotensin converting enzyme inhibitors, and four were on $\beta$ blockers. Pharmacological treatment was not altered for three months before and during the duration of the study in any subject.

The mean (SD) radionuclide left ventricular ejection fraction was $32.0(10.4) \%$. Cardiac echocardiography showed that left ventricular fractional shortening was $23.1(2.9) \%$ and the left ventricular end diastolic dimension, 60.6 (4.9) $\mathrm{mm}$

The study was designed as a random order crossover comparison of eight weeks of localised training (training phase) and eight weeks of restricted activity (detraining phase). As a prestudy assessment before this crossover study, our patients underwent a cardiopulmonary test with an upright electrical ergometer and a plantar flexion exercise test with ${ }^{31} \mathrm{P}$-MRS. Thereafter, they were enrolled either in the training phase or detraining phase. Four patients were in the training first group, and the other three were in the detraining first group.

Seven normal control subjects also underwent both tests done in the prestudy assessment. The mean (SD) age of normal subjects was 54.1 (6.0) years (range 48 to 64 years) and was not significantly different from the patients' mean age. Three of them were male and four were female. Their mean height was 156.6 $(7.2) \mathrm{cm}$ and body weight $52.8(12.4) \mathrm{kg}$. They were all healthy and did not take any medication. They did not habitually participate in sports.

TRAINING PROTOCOL

The training protocol consisted of repetitive isotonic right foot plantar flexion exercise at a rate of 40 per minute. Patients performed six minutes of plantar flexion as one set. The training routine consisted of four sets per day, five to seven days per week. For this study, we designed an original plantar flexion training apparatus in which loads could be changed in 5 $\mathrm{kg}$ increments, from 5 to $30 \mathrm{~kg}$, by adjusting springs. Patients began localised training with loads of 5,10 , or $15 \mathrm{~kg}$ and they were instructed to gradually increase the load as much as they could during the training phase. The initial load of the training apparatus was set at a moderate level so that patients could perform easily. Patients were instructed to increase the load of the apparatus as much as they could. We lent this apparatus and a metronome to the patients so they could train at home. To ensure that training proceeded as planned, we maintained contact with patients by phone once or twice a week and also asked the patients to keep diaries.

PHOSPHORUS-31 NUCLEAR MAGNETIC RESONANCE SPECTROSCOPY

${ }^{31} \mathrm{P}-\mathrm{MRS}$ was performed by using an $80 \mathrm{~mm}$ surface coil in a $55 \mathrm{~cm}$ bore, 1.5 Tesla superconducting magnet (Siemens Magnetom $1.5 \mathrm{~T})$. Shimming was adjusted by using ${ }^{1} \mathrm{H}$ (proton). Spectra were obtained with a pulse width of $500 \mu \mathrm{s}$, a transmitter voltage of $20.0 \mathrm{~V}$, and a repetition time of $2000 \mathrm{~ms}$. Each spectrum consisted of an average of 16 scans. One measurement required about 40 seconds. Since only the relative changes of the high energy phosphates were evaluated, correction for saturation was not performed. Phosphocreatine (PCr) is expressed as standardised $\mathrm{PCr},[\mathrm{PCr}] /([\mathrm{PCr}]+[\mathrm{Pi}])$, where $\mathrm{Pi}$ is inorganic phosphate. The muscle $\mathrm{pH}$ was calculated from the changes in the chemical shifts of $\mathrm{Pi}$ relative to $\mathrm{PCr} \quad(\mathrm{pH}=6.75+\log$ $[\{\sigma-3.27\}\{5.69-\sigma\}]$, where $\sigma(\mathrm{ppm})$ is the chemical shift from Pi to PCr).

EXERCISE TESTING PROTOCOLS FOR ${ }^{31} \mathrm{P}-\mathrm{MRS}$ STUDIES

First, using magnetic resonance imaging (MRI), the maximum calf flexor muscle cross sectional area was determined. The patients then performed right foot plantar flexion exercise 40 times per minute, and muscle energy metabolism was studied with ${ }^{31} \mathrm{P}-\mathrm{MRS}$, a surface coil being placed under the right calf. The patient's right foot was placed on a pedal attached by a pulley system to the load. During each plantar flexion, the load was lifted $5 \mathrm{~cm}$. The patients were secured by belts during the test to immobilise the trunk.

The supine plantar flexion test consisted of two exercises: (1) a multistage incremental exercise test; (2) a constant load exercise test. After the first incremental exercise test, patients rested for at least 30 minutes before the constant load exercise test. The incremental exercise was performed according to a symptom limited protocol. The load varied according to maximum calf area. The initial load was set at $0.05 \mathrm{~kg} / \mathrm{cm}^{2}$ calf area. It was then increased every minute by $0.05 \mathrm{~kg} / \mathrm{cm}^{2}$ calf area $\left(1 \mathrm{~J} / \mathrm{min} / \mathrm{cm}^{2}\right)$. Thus, between the training phase and the detraining phase, the absolute load increment per minute changed if maximum calf area changed, but the incremental load per unit of area stayed the same for all patients. In relation to the constant load exercise test, regardless of changes in maximum calf area between the training and detraining phases, the load determined by 
prestudy assessment $-70 \%$ of maximum load achieved during the incremental exercise-was employed in both phases. Patients performed the constant load test for six minutes. The fatigue score at the end of plantar flexion exercise was evaluated using the new Borg scale. ${ }^{19}$

CALF BLOOD FLOW

Within five days after the ${ }^{31} \mathrm{P}-\mathrm{MRS}$ test, strain gauge plethysmography was performed during the two exercise protocols, that is, the incremental exercise test and the constant load exercise test. We used two inflation cuffs, with the upper cuff secured around the thigh and the lower cuff secured around the ankle. When the upper cuff was inflated to $40 \mathrm{~mm} \mathrm{Hg}$, venous outflow was obstructed; when the lower cuff was inflated to $200 \mathrm{~mm} \mathrm{Hg}$, arterial inflow to the foot was obstructed. At the end of each stage in the incremental exercise test and every minute in the constant load exercise test, calf blood flow was measured while interrupting plantar flexion exercise for five seconds. Calf blood flow was determined from the rate of change in calf circumference and was expressed as $\mathrm{ml} / 100 \mathrm{ml} / \mathrm{min}$.

MAXIMUM VOLUNTARY CALF CONTRACTION

The force of maximum voluntary contraction of the calf $(\mathrm{kg})$ was determined using a load cell (LC 1205-K 200, A\&D Co, Tokyo, Japan). Measurement was performed with the pulley system used to evaluate calf muscle metabolism (described above).

\section{CARDIOPULMONARY EXERCISE TEST}

Peak $\dot{\mathrm{VO}}_{2}$ and ventilatory anaerobic threshold were measured on an upright electrical ergometer (Corival 400 Lobe bv, Groningen, The Netherlands) using a breath by breath respiratory gas analyser AE-280 (Minato Medical Science Co, Osaka, Japan). Patients underwent cardiopulmonary tests during the prestudy assessment, the training phase, and the detraining phase. Resting heart rate, resting blood pressure, peak work load, peak heart rate, and peak blood pressure were also measured. Exercise was performed employing a $15 \mathrm{~W} / \mathrm{min}$ ramp protocol after three minutes of warm up exercise at $0 \mathrm{~W}$. Ventilatory anaerobic threshold was determined using the V-slope method. ${ }^{20}$

HORMONAL FACTORS

Before the cardiopulmonary test, after at least 30 minutes of rest, plasma noradrenaline, adrenaline, plasma renin activity (PRA), aldosterone, and atrial natriuretic factor (ANF) concentrations were measured in the training phase and the detraining phase.

STATISTICAL METHODS

All data were analysed with a commercial statistical package (StatView-J 4.11, Abacus Concepts), and we compared the training phase and the detraining phase. Repeated measures analysis of variance (ANOVA) was used to compare changes of standardised phosphocreatine, intracellular $\mathrm{pH}$, and blood flow during calf plantar flexion exercise in the training and detraining phases. Concerning the incre-
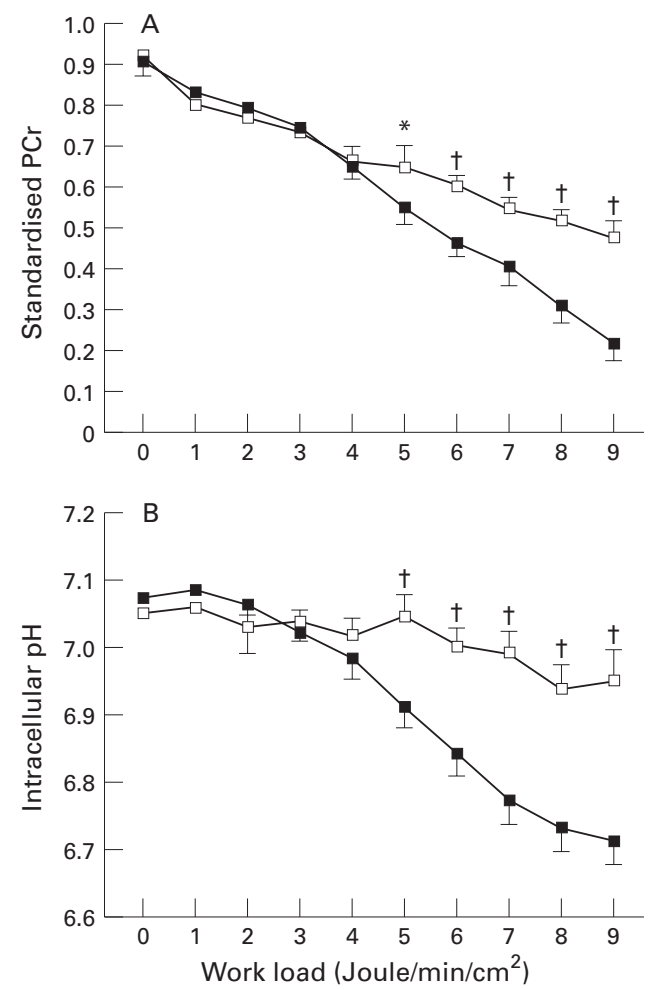

Figure 1 Comparison of standardised phosphocreatine $(P C r)$ utilisation $(A)$ and intracellular $p H(B)$ in incremental exercise between patients with chronic heart failure and normal control subjects. There was no significant difference between the two groups in either standardised $\mathrm{PCr}$ or intracellular $\mathrm{pH}$ by repeated measures analysis of variance (ANOVA). Data on exercise ranging from 0 to $9 \mathrm{~F} / \mathrm{min} / \mathrm{cm}^{2}$ are presented. Since all patients could complete at least $6 \mathrm{~F} / \mathrm{min} / \mathrm{cm}^{2}$, data for 0 to $6 \mathrm{f} / \mathrm{min} / \mathrm{cm}^{2}$ were used to compare these two groups by repeated measures ANOVA. When matched points were compared, both standardised $\mathrm{PCr}$ values and intracellular $p H$ were significantly different at 5 to $9 \mathrm{f} / \mathrm{min} / \mathrm{cm}^{2} .{ }^{\star} p<0.05$, $+p<0.01$, compared by unpaired t test. Empty squares, normal control subjects; filled squares, patients with chronic heart failure.

mental exercise test, data for 0 to $6 \mathrm{~J} / \mathrm{min} / \mathrm{cm}^{2}$ were used because all patients could complete at least $6 \mathrm{~J} / \mathrm{min} / \mathrm{cm}^{2}$. The paired $t$ test was also used to compare changes of other factors between the training phase and the detraining phase. In prestudy assessment, comparison between cardiac patients and normal subjects was made with an unpaired $t$ test. Statistical significance was assumed for $\mathrm{P}$ values $<0.05$. Data are expressed as mean (SEM).

\section{Results}

PRESTUDY ASSESSMENT

Our patients showed a significantly lower peak $\dot{\mathrm{VO}}_{2}$ and ventilatory threshold than normal control subjects (peak $\dot{\mathrm{VO}}_{2} 24.1$ (1.6) $v 32.0$ (2.6) $\mathrm{ml} / \mathrm{kg} / \mathrm{min}, \mathrm{p}<0.01$; ventilatory threshold $16.4 \quad(1.3) \quad v \quad 22.6 \quad(2.1) \quad \mathrm{ml} / \mathrm{kg} / \mathrm{min}$, $\mathrm{p}<0.05)$. During the plantar flexion exercise, the metabolic responses were significantly different between normal subjects and patients, during both incremental exercise (fig 1) and constant load exercise (fig 2). 

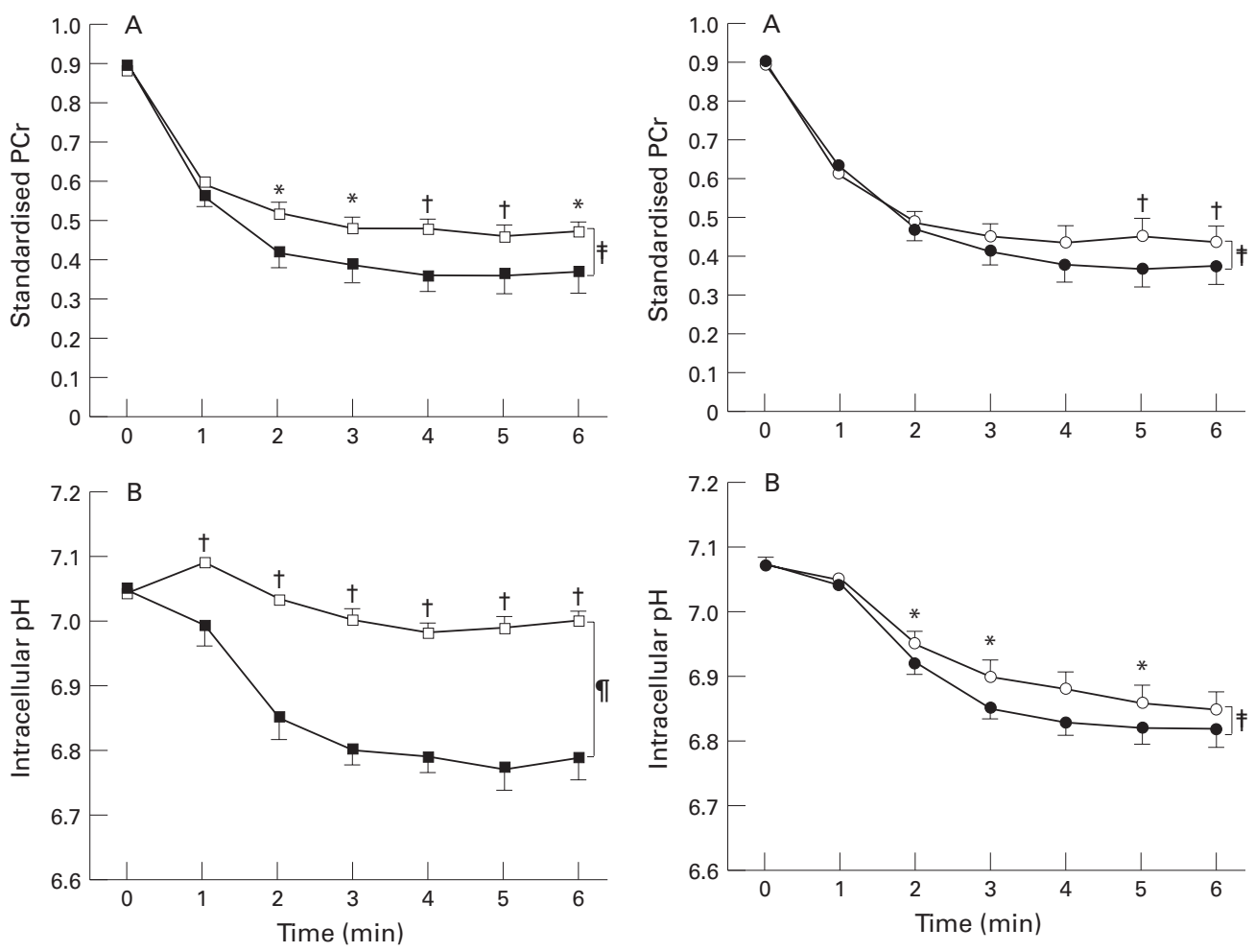

Figure 2 Comparison of standardised phosphocreatine (PCr) utilisation $(A)$ and intracellular $p H(B)$ in constant load exercise test between patients with chronic heart failure and normal control subjects. Patients showed more depletion than normal control subjects by repeated measures analysis of variance (ANOVA). Comparing matched points, standardised $P C r$ values were significantly different at 2 to 6 minutes, and intracellular $\mathrm{pH}$ at 1 to 6 minutes. $\ddagger p=0.01, \Phi p<0.01$ by repeated measures ANOVA; ${ }_{\star}^{*} p<0.05, \dagger p<0.01$, compared by unpaired t test. Empty squares, normal control subjects; filled squares, patients with chronic heart failure.

METABOLIC CHANGES EVALUATED WITH ${ }^{31} \mathrm{P}$-MRS The skeletal muscle metabolic responses of the training phase and the detraining phase were compared.

\section{Incremental exercise test}

There was a tendency towards higher $\mathrm{pH}$ after training $(\mathrm{p}<0.10$ by repeated measures ANOVA). Comparing matched work loads, intracellular $\mathrm{pH}$ was higher mainly for low intensity work loads after training versus detraining $\left(\mathrm{p}<0.05\right.$ at 2 and $\left.3 \mathrm{~J} / \mathrm{min} / \mathrm{cm}^{2}\right)$. Standardised phosphocreatine did not change significantly during plantar flexion exercise from the training phase to the detraining phase $(\mathrm{p}=$ NS by repeated measures ANOVA).

\section{Constant load exercise test}

The decrease in standardised phosphocreatine during the plantar flexion exercise (fig 3A) was significantly smaller after training $(\mathrm{p}<0.05$ by repeated measures ANOVA). When matched points were compared, there were significant differences at 5 and 6 minutes $(p<0.01)$. After training, intracellular $\mathrm{pH}$ also showed a blunted decrease during exercise (fig 3B; $\mathrm{p}<0.05$ by repeated measures ANOVA). Comparing matched points, there were significant differences between the training phase and the detraining phase at 2, 3 , and 5 minutes

Figure 3 Effects of localised training on standardised phosphocreatine (PCr) utilisation (A) and intracellular $\mathrm{pH}$ (B) in constant load exercise test. There was less standardised PCr depletion as well as less intracellular $p H$ reduction after training. $\ddagger p<0.05$, compared by repeated measures analysis of variance. ${ }^{\star} p<0.05,+p<0.01$, comparing matched points by paired t tests. Empty circles, training phase; filled circles, detraining phase.

$(\mathrm{p}<0.05)$ and at 6 minutes $(\mathrm{p}<0.06)$. Even when the standardised phosphocreatine at 6 minutes (steady state value) was adjusted by the individual ratio of training/detraining maximum calf area ([training phase $\mathrm{PCr}$ value] $v$ [detraining phase $\mathrm{PCr}$ value] $\times$ the ratio of training/detraining MCA), there was a significant difference between the training phase and the detraining phase in the constant load exercise test $(0.44(0.04) v 0.39(0.05), \mathrm{p}<0.05)$.

LOCALISED TRAINING EFFECTS ON BLOOD FLOW, NEW BORG SCALE, AND OTHER FACTORS Data for these are shown in table 1.

\section{Incremental exercise test}

There was no significant difference in calf blood flow change between the training phase and the detraining phase by repeated measures ANOvA, and when matched work loads were compared by paired $t$ test there was no difference between the two phases either. The new Borg scale did not change significantly. When work loads were expressed per unit of calf cross sectional area, the peak work load $\left(\mathrm{J} / \mathrm{min} / \mathrm{cm}^{2}\right)$ did not change significantly. However, the absolute peak work load $(\mathrm{J} / \mathrm{min})$ was higher after training $(\mathrm{p}<0.05)$.

Constant load exercise test

Blood flow in the training phase and the detraining phase did not differ (fig $4 ; \mathrm{p}=$ NS by repeated measures ANOVA), and when matched 
Table 1 Data for right calf between the training phase and the detraining phase

\begin{tabular}{|c|c|c|}
\hline & Training phase & Detraining phase \\
\hline \multicolumn{3}{|l|}{ Blood flow ( $\mathrm{ml} / 100 \mathrm{ml} / \mathrm{min})$} \\
\hline Rest & $2.5(0.4)$ & $2.7(0.4)$ \\
\hline $6 \mathrm{~J} / \mathrm{min} / \mathrm{cm}^{2}$ & $26.1(3.0)$ & $30.2(4.6)$ \\
\hline \multicolumn{3}{|l|}{ (Constant) } \\
\hline Rest & $2.5(0.4)$ & $2.7(0.4)$ \\
\hline $6 \mathrm{~min}$ & $27.6(2.4)$ & $29.8(2.7)$ \\
\hline $\operatorname{MCA}\left(\mathrm{cm}^{2}\right)$ & $55.6(2.4)^{\star}$ & $53.8(2.6)$ \\
\hline MVC $(\mathrm{kg})$ & $44.6(5.2)$ & $39.5(4.0)$ \\
\hline Peak work load in incremental exercise $\left(\mathrm{J} / \mathrm{min} / \mathrm{cm}^{2}\right)$ & $9.7(0.8)$ & $8.9(0.8)$ \\
\hline Absolute peak work load in incremental exercise $(\mathrm{J} / \mathrm{min})$ & $539.8(49.2)^{\star}$ & $476.8(44.7)$ \\
\hline \multicolumn{3}{|l|}{ New Borg scale $(/ 10)$} \\
\hline Incremental & $7.6(0.3)$ & $8.6(0.2)$ \\
\hline Constant & $3.9(0.3)^{\star}$ & $5.7(0.6)$ \\
\hline
\end{tabular}

${ }^{\star} \mathrm{p}<0.05 v$ the detraining phase. Data are mean values $(\mathrm{SEM})$. Blood flow in incremental test was compared between data at rest and at $6 \mathrm{~J} / \mathrm{min} / \mathrm{cm}^{2}$, because all patients could complete at least 6 $\mathrm{J} / \mathrm{min} / \mathrm{cm}^{2}$

MCA, maximum cross sectional area; MVC, maximum voluntary contraction.

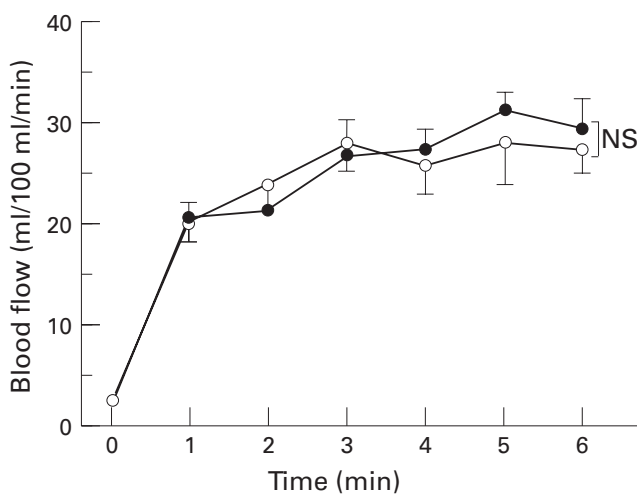

Figure 4 Effects of localised training on calf blood flow in constant load exercise test. There was no difference between the training phase and the detraining phase by repeated measures analysis of variance $(p=N S)$. Comparing matched points, there were no significant changes. Empty circles, training phase; filled circles, detraining phase.

points were compared, there was no significant difference between the two phases. The new Borg scale improved significantly after training $(\mathrm{p}<0.05)$.

Maximum calf cross sectional area

The maximum calf cross sectional area significantly increased after training $(p<0.05)$.

Maximum voluntary contraction

The mean value of the force of maximum voluntary contraction increased after training, although not significantly.

Training loads

Patients began their training at the mean load of $10.7(2.3) \mathrm{kg}$. All were able to increase the load subsequently, and the final mean load was increased to $18.6(1.7) \mathrm{kg}$.

HAEMODYNAMICS AND NEUROHORMONAL

FACTORS

We examined whether localised training affected systemic exercise capacity and neurohormonal factors. During the upright ergometer test, cardiopulmonary data did not change after training (table 2).

At the end of the training phase, we measured heart rate, blood pressure, and oxygen uptake during six minutes of plantar flexion with our original apparatus. Heart rate
Table 2 Haemodynamic data

\begin{tabular}{lcc}
\hline & Training phase & Detraining phase \\
\hline Peak $\dot{\mathrm{VO}}_{2}(\mathrm{ml} / \mathrm{kg} / \mathrm{min})$ & $23.4(2.2)$ & $22.1(1.7)$ \\
$\mathrm{VT}(\mathrm{ml} / \mathrm{kg} / \mathrm{min})$ & $15.7(1.1)$ & $15.5(0.8)$ \\
Peak work load (watt) & $131.7(15.2)$ & $127.0(13.8)$ \\
Heart rate (beats/min) & & \\
$\quad$ Rest & $76.7(3.9)$ & $86.0(5.4)$ \\
$\quad$ Peak & $159.6(14.5)$ & $157.6(15.4)$ \\
Blood pressure (mm & & \\
$\quad$ Hg) & & \\
Rest & $132.1(7.1)$ & $130.6(8.1)$ \\
Peak & $197.7(10.0)$ & $193.1(8.1)$ \\
\hline
\end{tabular}

Data are mean values (SEM). There was no significant change between the training phase and the detraining phase. All data were measured during upright ergometer exercise test.

Peak $\dot{\mathrm{VO}}_{2}$, peak oxygen uptake; VT, ventilatory anaerobic threshold.

increased by $19.3(6.8) \%$ and blood pressure by $19.3(1.4) \%$ of the resting value. Oxygen uptake was $30.2(1.6) \%$ of peak $\mathrm{VO}_{2}$.

Neurohormonal factors showed no significant changes when comparing the training phase and detraining phase: plasma noradrenaline 840.9 (225.1) v 758.4 (134.4) pg/ml (NS); adrenaline $55.1(15.1)$ v 70.9 (23.2) $\mathrm{pg} / \mathrm{ml}$ (NS); PRA 9.8 (4.6) $v 8.1$ (3.5) pg/ml.h (NS); aldosterone 117.9 (12.6) $v 108.6(9.8) \mathrm{pg} / \mathrm{ml}$ (NS); and ANF 24.5 (6.5) $v 19.6$ (8.3) pg/ml (NS). The normal values of these hormones in our institute are as follows: noradrenaline 90 to $420 \mathrm{pg} / \mathrm{ml}$, adrenaline 0 to $80 \mathrm{pg} / \mathrm{ml}$, PRA 0.2 to $2.7 \mathrm{ng} / \mathrm{ml} . \mathrm{h}$, aldosterone 56.9 to 150.3 $\mathrm{pg} / \mathrm{ml}$, and ANF 0 to $43 \mathrm{pg} / \mathrm{ml}$.

\section{Discussion}

Training for patients with chronic heart failure has been investigated for several years. Initially, large muscle group training such as bicycle ergometer exercise was investigated. The results showed increasing systemic exercise time and peak $\mathrm{VO}_{2}$ without improvement in cardiac function. Sullivan et $a l^{5}$ speculated that peripheral factors played an important role in improving exercise capacity. Thereafter peripheral factors-such as muscle metabolism, vascular resistance, and so on-have attracted more attention and localised skeletal muscle training has been examined. However, to our knowledge, there has been only one localised training study on the lower extremities, by Magnusson et $a l,{ }^{17}$ who reported that single thigh training in chronic heart failure improved exercise capacity. Employing a muscle biopsy technique, they also showed that there were histochemical changes in thigh muscle after training. Since the calf muscle group has a naturally greater proportion of oxidative fibres ${ }^{11-13}$ and its metabolic responses during exercise are different from those of upper extremities, ${ }^{14-16}$ we speculated that the training effect on this muscle group might be different from that of the forearm.

Our study showed that the decrease in intracellular $\mathrm{pH}$ diminished. Several effects of training have been reported, including reductions in lactate production, ${ }^{21}{ }^{22}$ increases in the lactate clearance rate ${ }^{23-25}$ and improvement of acid buffering capacity. ${ }^{26}$ These mechanisms may have contributed to the improvement in intracellular $\mathrm{pH}$ observed in our study. The 
decrease in standardised phosphocreatine was also smaller after training. This suggested that there was improvement of oxidative capacity in our study. ${ }^{18}$

To evaluate the metabolic response to localised exercise, with ${ }^{31} \mathrm{P}-\mathrm{MRS}$, we have advocated the usefulness of combining two exercise protocols, an incremental exercise protocol and a $70 \%$ maximum, constant load exercise protocol. Our previous data suggested that during calf plantar flexion exercise, $70 \%$ of the maximum work load was a suitable value for comparing metabolic differences between cardiac patients and normal subjects. ${ }^{27}$ In the present study, the $70 \%$ maximum constant load exercise resulted in more definite metabolic improvements than incremental exercise. We suggest that the combination of these two exercise protocols is also useful for studying training effectiveness in patients with chronic heart failure.

Nishida et $a l^{28}$ proposed that if the same absolute load was imposed on all subjects regardless of muscle cross sectional area, the load per unit of muscle fibre would be less in subjects with a greater muscle cross sectional area. As far as we know, there has been no localised training study adjusting for muscle cross sectional area. Though our incremental exercise test imposed a work load adjusted in this way, there was still a tendency towards higher $\mathrm{pH}$ after training. In the constant load exercise test, we did not adjust for muscle cross sectional area in order to compare the metabolic responses to the same absolute work load of the training phase and the detraining phase. However, after applying this adjustment a significant difference in standardised phosphocreatine remained. Thus the training effect on muscle metabolism could not be explained by the changes of muscle cross sectional area alone.

Our study showed that calf blood flow did not change in spite of an improvement in muscle metabolism. Minotti et $a l^{9}$ also reported that there was no significant change in blood flow after localised forearm training. On the other hand, Sullivan et $a l^{5}$ reported that leg blood flow increased after training with a bicycle ergometer. Both we and Minotti et $a l^{9}$ trained a relatively small muscle group and evaluated blood flow with strain gauge plethysmography, whereas Sullivan et $a l^{5}$ trained a large muscle group with an ergometer and measured blood flow with a thermodilution catheter. We believe that blood supply to small working muscle groups, such as those of the forearm or calf, is sufficient even in cardiac patients during localised exercise.

In incremental exercise, because of the symptom limited protocol, the score of the new Borg scale at peak exercise did not change between the training phase and the detraining phase. On the other hand, in constant load exercise, the score improved significantly. Thus patients were able to perform plantar flexion exercise with less effort after training. In previous localised training studies ${ }^{9}{ }^{10}$ fatigue scores were not evaluated.
Using ${ }^{31} \mathrm{P}-\mathrm{MRS}$, Minotti et $a l^{9}$ and Stratton et $a l^{10}$ investigated localised forearm training. Both groups found that training improved the forearm metabolic response during exercise. Adamopoulos et $a l^{18}$ used ${ }^{31} \mathrm{P}-\mathrm{MRS}$ to examine large muscle group training in patients with chronic heart failure. They suggested that there was significant muscle improvement during calf plantar flexion exercise after training. They used a bicycle ergometer for training, whereas plantar flexion exercise was used to assess muscle metabolism. We employed the same exercise mode in training and metabolic evaluation, and we found improvement in muscle metabolism after training. Regarding the training method, our localised training programme induced only slight cardiac stress when compared with large muscle group training, such as bicycle ergometer exercise. It therefore appears that our training programme could be advantageous for patients with chronic heart failure who cannot perform high intensity exercise training because of their poor cardiac reserve.

\section{STUDY LIMITATIONS}

The patient population was relatively small, as only a small number of patients agreed to follow the long strict study protocol. We therefore employed a crossover design for the study because it required fewer subjects. ${ }^{29}$

Our patients with chronic heart failure showed a relatively high mean value for peak $\dot{\mathrm{V}} \mathrm{O}_{2}$. In relation to neurohormonal factors, the value of ANF was within the normal range, suggesting that our chronic heart failure patients were well controlled. However, as we showed in the prestudy assessment, their left ventricular ejection fraction was clearly decreased, and their skeletal muscle metabolic response during plantar flexion exercise showed a significant decrease in standardised phosphocreatine and intracellular $\mathrm{pH}$ compared with age matched normal subjects, thus indicating that they were suitable for training intervention.

We did not use the non-trained leg as a control. Minotti et $a l^{9}$ and Stratton et $a l^{10}$ reported in their localised forearm training in patients with chronic heart failure that there was no significant metabolic change in the non-trained arm. On the other hand, Ploutz et $a l^{30}$ suggested that localised resistance training in normal subjects improved non-trained distant muscle groups. The proposed mechanism was neural. In view of these uncertainties we did not employ the non-trained leg as control.

CONCLUSIONS

In patients with chronic heart failure, localised calf skeletal muscle training improved muscle oxidative capacity without changes in calf blood flow. The calf fatigue scale also improved significantly after training. Since cardiac patients are often limited by leg fatigue, this training method may improve muscle fatigue symptoms occurring in the course of daily activities. Patients whose cardiac function is impaired may be provided with additional safety benefits by localised training, since it does not have an important influence on the heart. 
We thank the Mutou Corporation for technical advice and support.

1 Massie BM, Kramer B, Haughom F. Acute and long-term effects of vasodilator therapy on resting and exercise hemodynamics and exercise tolerance. Circulation 1981; 64:1218-26.

2 Massie BM, Conway M, Yonge R, Frostick S, Ledingham J, Sleight $\mathrm{P}$, et al. Skeletal muscle metabolism in patients with congestive heart failure: relation to clinical severity and blood flow. Circulation 1987;76:1009-19.

3 Wilson JR, Fink L, Maris J, Ferraro N, Power-Vanwart J, Eleff $\mathrm{S}$, et al. Evaluation of energy metabolism in skeleta muscle of patients with heart failure with gated phosphorus-31 nuclear magnetic resonance. Circulation 1985;71:57-62.

4 Mancini DM, Ferraro N, Tuchler M, Chance B, Wilson JR. Detection of abnormal calf muscle metabolism in patients with heart failure using phosphorus-31 nuclear magnetic resonance. Am 7 Cardiol 1988;62:1234-40.

5 Sullivan MJ, Higginbotham MB, Cobb FR. Exercise training in patients with severe left ventricular dysfunction: hemodynamic and metabolic effects. Circulation 1988;78: h06-15.

6 Arvan S. Exercise performance of the high risk acute myocardial infarction patient after cardiac rehabilitation. myocardial infarction patient

7 Coats AJS, Adamopoulos S, Meyer TE, Conway J, Sleight P. Effects of physical training in chronic heart failure. Lancet 1990;335:63-6.

8 Coats AJS, Adamopoulos S, Radaelli A, McCance A, Meyer TE, Bernardi L, et al. Controlled trial of physical training in chronic heart failure: exercise performance, hemodynamics, ventilation, and autonomic function. Circulation 1992; 85:2119-31.

9 Minotti JR, Johnson EC, Hudson TL, Zuroske G, Murata $\mathrm{G}$, Fukushima E, et al. Skeletal muscle response to exercise training in congestive heart failure. F Clin Invest 1990;86: 751-8.

10 Stratton JR, Dunn JF, Adamopoulos S, Kemp GJ, Coats AJS, Rajagopalan B. Training partially reverses skeletal muscle metabolic abnormalities during exercise in heart muscle metabolic abnormalities during

11 Edström L, Nyström B. Histochemical types and sizes of fibres in normal human muscles. Acta Neurol Scand fibres in normal

12 Gollnick PD, Sjödin B, Karlsson J, Jansson E, Saltin B. Human soleus muscle: a comparison of fiber composition and enzyme activities with other leg muscles. Pflugers Arch 1974;348:247-55.

13 Costill DL, Daniels J, Evans W, Fink W, Krahenbuhl G, Saltin B. Skeletal muscle enzymes and fiber composition in male and female track athletes. F Appl Physiol 1976;40:149-54.

14 Ahlborg G, Jensen-Urstad M. Metabolism in exercising arm vs. leg muscle. Clin Physiol 1991;11;459-68.
15 Glasheen JW, McMahon TA. Arms are different form legs: mechanics and energetics of human hand-running. $f$ Appl Physiol 1995;78:1280-7.

16 Nishijima H, Yonezawa K, Yamada Y, Okita K, Ohtsubo M, Kitabatake A. Anaerobic threshold during upright bicycle exercise is related to calf, but not to the forearm muscle metabolism [abstract]. F Heart Failure 1995;2:83.

17 Magnusson G, Gordon A, Kaijser L, Sylvén C, Isberg B, Karpakka J, et al. High intensity knee extensor training, in patients with chronic heart failure. Eur Heart $\mathcal{F}$ 1996;17: 1048-55.

18 Adamopoulos S, Coats AJS, Brunotte F, Arnolda L, Meyer $\mathrm{T}$, Thompson $\mathrm{CH}$, et al. Physical training improves skeletal muscle metabolism in patients with chronic heart failure. $\mathcal{f}$ Am Coll Cardiol 1993;21:1101-6.

19 Borg GA. Psycho-physical bases of perceived exertion. Med Sci Sports Exerc 1982;14:377-81.

20 Beaver WL, Wasserman K, Whipp BJ. A new method for detecting anaerobic threshold by gas exchange. $f \mathrm{Appl}$ Physiol 1986;60:2020-7.

21 Favier RJ, Constable SH, Chen M, Holloszy JO. Endurance exercise training reduces lactate production. F Appl Physiol 1986;61:885-9.

22 Holloszy JO, Coyle EF. Adaptations of skeletal muscle to endurance exercise and their metabolic consequences. $f$ Appl Physiol 1984;56:831-8.

23 Donovan CM, Brooks GA. Endurance training affects lactate clearance not lactate production. Am f Physiol 1983;244:E83-92.

24 Donovan CM, Pagliassotti MJ. Enhanced efficiency of lactate removal after endurance training. 7 Appl Physiol 1990;68:1053-8.

25 Pagliassotti MJ, Donovan CM. Role of cell type in net lactate removal by skeletal muscle. Am f Physiol 1990;258: E635-42.

26 Sharp RL, Costill DL, Fink WJ, King DS. Effect of eight weeks of bicycle ergometer sprint training on human muscle buffer capacity. Int 7 Sports Med 1986;7:13-17.

27 Yonezawa K, Okita K, Ohtsubo M, Kohya T, Nishijima $\mathrm{H}$. Submaximal endurance of calf muscle, as compared to maximal work rate, is disproportionately reduced in cardiac patients [abstract]. Circulation 1994;90:I-658.

28 Nishida $M$, Nishijima H, Yonezawa K, Sato I, Anzai T, Okita $\mathrm{K}$, et al. Phosphorus-31 magnetic resonance spectroscopy of forearm flexor muscles in student rowers using an exercise protocol adjusted for differences in crosssectional area. Eur 7 Appl Physiol 1992;64:528-33.

29 Hills M, Armitage P. The two-period cross-over clinical trial. Br f Clin Pharmacol 1979;8:7-20.

30 Ploutz LL, Tesch PA, Biro RL, Dudley GA. Effect of resistance training on muscle use during exercise. $\mathcal{F}$ Appl Physiol 1994;76:1675-81. 